\title{
Group Atmosphere, Shared Understanding, and Team Conflict in Short Duration Virtual Teams
}

\author{
Fang $\mathrm{He}$ \\ Enterprise Risk Management \\ USAA \\ San Antonio, Texas \\ helen0908@yahoo.com
}

\author{
Souren Paul \\ College of Engineering and \\ Computing \\ Nova Southeastern University \\ Fort Lauderdale, Florida \\ souren.paul@gmail.com
}

\author{
Alan R. Dennis \\ Kelly School of Business \\ Indiana University \\ Bloomington, Indiana \\ ardennis@indiana.edu
}

\begin{abstract}
In this study we examine the influence of group atmosphere on perceived team conflict and the development of shared understanding in short duration virtual teams. We conducted a laboratory experiment with 24 short duration virtual teams that were engaged in data model development task. The findings of the study suggest that group atmosphere has strong influence on both development of shared understanding and perceived team conflict. In addition, we also find that national cultural diversity facilitates the development of shared understanding in virtual teams.
\end{abstract}

\section{Introduction}

Virtual teams are teams of geographically, organizationally and/or temporally dispersed individuals brought together by information and telecommunications technologies to accomplish one or more organizational tasks (Powell, Piccoli, and Ives, 2004). With globalization of business, virtual teams have become very common for global business organizations. The virtual teams usually consist of members of diverse background. On many occasions virtual teams are formed to solve specific technical problems or address emergency management situation. In these situations distributed expertise are combined form ad hoc teams. Ad hoc virtual teams play crucial role in knowledge works (Lind, 1999), emergency response situations, and in providing temporary support on technical problems. However, developing trust, cohesion and building relationships are difficult in short duration virtual work (Dube and Pare, 2002). De Pillis and Furumo (2007) find that for projects of short duration, virtual teams have lower performance than face-to-face teams. Thus, it is important to understand how diverse members of ad hoc virtual teams share information, and perform effectively.
The members of virtual teams are brought together by information and telecommunication technologies to accomplish one or more organizational tasks. These technologies enable geographically dispersed individuals to interact with each other. However, technology mediated interactions add challenges in the functioning of the virtual teams. Diversity is an inherent aspect of these teams. Although virtual teams with surface level diversity (observable differences, such as gender, race) can become cohesive over time, similar results have not been observed for the teams with deep-level diversity (differences that are not readily observable, such as values, attitudes, experience) (Chidambaram, 2005). Members of culturally diverse virtual teams have differences in norms, beliefs, and experiences which present challenges for achieving cohesion and harmony in these teams. Moreover, the members of these teams interact using communication media some of which do not support the transmission of non-verbal cues (such as, gestures, facial expressions) and constrain the team members to rely primarily on written interactions. The development of shared understanding is quite challenging in these teams. Shared understanding helps the team members to avoid conflict and improve team performance (Hinds and Wiseband, 2003). Stout, Cannon-Bower, Salas, and Milanovich (1999) suggest that the development of shared mental models provide team members with a common understanding of the tasks and information requirements. A significant number of virtual teams are engaged in short-duration and non-repetitive tasks, such as providing one time technical support, responding to emergency situations. Development of shared mental model and hence shared understanding is quite challenging in these teams. Similarity, shared experience, information sharing, the ability to identify and resolve misunderstandings are some of the determinants of shared understanding in virtual teams (Hinds and Wiseband, 2003). In this 
research, we examine the effects of team diversity on the development of shared understanding.

Prior research demonstrates the effect of group atmosphere on the outcomes of group work. Jehn, Rispens, and Thetcher (2010) find that the perception of group atmosphere mediates the effect of conflict asymmetry on individual member's satisfaction with team work. Jehn and Mannix (2001) demonstrate that group atmosphere mediates the relationship of individual conflict asymmetry with team performance. Prior studies have demonstrated the positive effects of group atmosphere on team work (Zarraga and Bonache, 2005). The construct of group atmosphere has not been studied comprehensively in the context of virtual teams. Gibson and Gibbs (2006) find that the negative effects of virtuality on innovation are mitigated by safe communication atmosphere in virtual teams. On the contrary, Paul and Ray (2006) find that group atmosphere aggravates manifested task conflict in virtual teams. We extend the prior studies on group atmosphere to examine its influence on shared understanding and conflict in virtual teams.

Thus, in this study, we attempt address the following research questions:

- Does group atmosphere influence conflict and shared understanding in short duration virtual teams?

- Does team diversity (cultural and educational specialization) influence perception of conflict and shared understanding in short duration virtual teams?

Our results suggest that for the short-duration virtual teams that we studied, group atmosphere has strong influence on team members' perception of conflict and shared understanding in the teams. In the next section, we discuss the theoretical background of our study and present our research hypotheses. Next, we discuss the research method, which is followed by the results. We end the paper with a discussion on the findings, limitations, and conclusions.

\section{Literature review and theory development}

Virtual teams use a variety of collaboration technologies, such as audio and video conferencing systems (e.g., Skype, Webex), instant messaging, electronic conferencing, and electronic mail. Some of these technologies use lean media such as instant messaging, electronic conferencing, and electronic mail. The use of lean media hinders transmission of non-verbal cues (e.g. gestures, facial expressions) and constrains the team members to rely primarily on written interactions (Han, et al., 2011). Poole, Holmes, and Desanctis (1991) found differences in the amount of conflict and conflict management behavior between the groups that used lean media technology and those who did not.

There are several antecedent conditions of conflict in teams, such as such as distance (Hinds and Bailey, 2003), group value consensus (Jehn and Mannix, 2001), informational and value diversity (Jehn, Northcraft, and Neale, 1999), demographic diversity (Pelled, Eisenhardt, and Xin, 1999), functional diversity (Pelled, Eisenhardt, and Xin, 1999), faultline strength (Thatcher, Jehn, and Zanutto, 2003), and cultural diversity (Stahl, Maznevski, Voigt, and Jonsen, 2009). Jehn and Mannix (2001) suggest that group atmosphere mediates the relationship between group value consensus and intra-group conflict. Not many studies have examined the role of group atmosphere in virtual teams. In this study, we focus on group atmosphere and its influence on conflict and shared reality in virtual teams. Both shared understanding and intra-group conflict shape the performance of virtual teams. The core constructs of our study are group atmosphere, team conflict, and shared understanding in virtual teams. We present brief literature reviews on these constructs and develop the hypotheses of this study.

\subsection{Team Conflict}

Conflict is broadly defined as the perception by the parties involved that they hold discrepant views or have interpersonal incompatibilities (Boulding, 1963). Conflict is a common aspect of team work. Although conflict has traditionally been viewed as a dysfunctional event, some studies highlight that certain level of conflict improves performance in non-routine and cognitive tasks (Pelled, Eisenhardt, and Xin, 1999; Jehn, 1995). Thus, conflict can be both functional and dysfunctional.

Conflict can be concerned with relationship issues or task issues (Guetzkow and Gyr, 1954; Jehn, 1997). Relationship conflicts arise from differences in personal taste, political preference, values and ideology, whereas task conflicts are conflicts about the distribution of resources, about procedures and policies, and about judgments and interpretation of facts (De Dreu and Weingart, 2003). In short-duration teams, task conflict tends to be more important because team members have limited time to socialize, and fewer prospects of building long term relationships.

Conflict can be either perceived or manifested (Pondy, 1967). Perceived conflict occurs when an individual recognizes that that conflict exists while manifested conflict occurs when conflict is expressed 
as an overt behavior. Perception of conflict refers to the cognitive aspect or the conceptualization of a conflict condition. Individuals associated with a conflict condition, become aware of conflict when oppositions or potential incompatibilities are not resolved to their satisfaction. In this study, we focus on perceived team conflict.

\subsection{Shared Mental Model and shared understanding}

Shared mental model of teams, also known as team mental model is defined as organized knowledge shared by the team members (Orasanu and Salas, 1993). Mohammed and Dumville (2001) define team mental model as 'team members' shared, organized understanding and mental representation of knowledge about key elements of the team's relevant environment" (page 90). Mathieu, Goodwin, Heffner, Salas, and Canon-Bowers (2000) discuss how the convergence of team- and task-based mental models strengthens team process and performance. Teambased shared mental model involves team-specific knowledge about teammates. This involves knowledge about teammates' skills, attitude, preferences, and tendencies. Task-based shared mental model involves knowledge about task procedures and strategies. In multi-cultural virtual teams, both team- and task-based mental models shape team processes. While the convergence of task-based mental models can help team members to manage task conflict constructively, the convergence of team-based mental model will reduce social dilemma and social identity and improve openness in the interaction of the team members. Researchers suggest that the existence of shared mental models help teams to improve performance, especially in high workload conditions (Stout, Cannon-Bower, Salas, and Milanovich, 1999). Klimoski and Mohammed (1994) suggest that the perception of having shared mental models motivate team related activities and promote trust. Researchers suggest that team members, engaged in solving any problem must develop a shared understanding of the problem situation (Orasanu, 1990). Stout et al. (1999) suggest that shared mental model enable team members to develop common understanding about tasks. Hinds and Wiseband (2003) define shared understanding in virtual team as "a collective way of organizing and communicating relevant knowledge, as a way of collaborating" (Hinds and Wiseband, 2003, page 23). Various dimensions of shared understanding have been proposed by Hinds and Wiseband (2003), such as common understanding about goals, shared understanding about task, shared understanding of the anticipated interaction among team members, shared understanding about the characteristics and activities of the team members. These different types of shared understanding can impact team performance (Hinds and Wiseband, 2003). In this study, we focus on shared understanding about interactions and activities of the team members.

\subsection{Group Atmosphere}

Participants in CMC develop impressions of others through textually conveyed information (Walther, 1996). Forming perceptions about other members and the online work environment is conceptualized as team atmosphere in this research. The concept of team atmosphere or team climate is not new in organizational studies. Organizational researchers have focused on 'facet-specific climates', such as climates for innovation (Bunce and West, 1995; Burningham and West, 1995). Jehn and Mannix (2001) introduce the construct of group atmosphere in their study on intra-group conflict. They identify trust, respect, cohesion, openness, and liking as the five underlying dimensions of the work environment. Jehn, Rispens, and Thatcher (2010) conceptualized group atmosphere as the "positive attitudes and conditions of a group's members about the level of trust, respect, and commitment in their group" (page 600). The importance of these factors in group work has been discussed in the literature; coordination in virtual teams is accomplished through trust (Jarvenpaa, Knoll, and Leidner, 1998); cohesion is associated with the performance of virtual teams (Powell, Piccoli, and Ives, 2004); openness is associated with collaborative conflict management in virtual teams (Montoya-Weiss, Massey, and Song, 2001). Group members' perception of group climate affects their group behavior and interactions (Choi, Price, and Vinokur, 2003). In a later study on conflicts on work groups, Jehn, Rispens, and Thatcher (2010) included respect, trust, and commitment as three major dimensions of group atmosphere. In this research, we focus on commitment and trust as two important elements of the group atmosphere in virtual teams. Relationship building in a team involves interaction processes designed to increase feelings of belonging to the team (Powell, Piccoli, and Ives, 2004). Once team members perceive the inclusiveness, they are committed to perform a better job. Trust involves interpersonal relationship building and plays a key role for effective information sharing in virtual settings. Trust occurs when a person is confident in and willing to act on the basis of the actions and decisions of others in the team (McAllister (1995). Trust have been considered as critical in managing people who cannot meet face-to-face (Handy, 1995); it facilitates effective interactions when 
members are willing to open themselves to each other and cooperate to solve a problem (Jarvenpaa, Knoll, and Leidner, 1998). If team members distrust each other, they may refuse to cooperate or make contributions essential to team performance (Davis, 2004).

Prior research on group climate suggests that group members' perception of climate affects their behavior and interactions (Choi et al. 2003). It has also been found that an individual's perceptions of work environment influence his/her work attitude on job involvement and commitment in organizations (Parker, Baltes, Young, Huff, Altmann, Lacost, and Roberts, 2003). Jehn and Mannix (2001) report that group atmosphere mediates the relationship between group value consensus and intragroup conflict. Based on prior research on group climate and group atmosphere, we suggest that members of virtual teams with positive perceptions of group atmosphere trust each other and are committed to group work. These teams will act as cohesive units and the individual members will tend to develop shared understanding and reach mutual agreement for working together. Hence:

Conjecture1: In short duration virtual teams, individual member's perception of favorable group atmosphere will have a positive relationship with the perception of shared understanding in the team.

Conjecture2: In short duration virtual teams, individual member's perception of favorable group atmosphere will have a negative relationship with the perception of team conflict.

\subsection{Virtual Team and Diversity}

Diversity is an inherent characteristic of global virtual teams. Diversity within a work group refers to its composition in terms of the distribution of demographic traits and cognitive differences manifested as surface-level and deep-level attributes (Chidambaram, 2005). Diversity is classified as surface level and deep level diversity (Harrison, Price, and Bell, 1998). Surface level diversity is defined as difference among team members in overt demographic characteristics, which include age, gender, and race/ ethnicity. Deep level diversity refers to differences among team members' psychological characteristics, including personalities, values, and attitudes (Jackson, May, and Whitney, 1995; Harrison et al, 1998). Clues to these latent individual differences are taken from members' interactions with one another as they unfold over time. These clues are expressed in behavioral patterns, verbal and nonverbal communications, and exchange of personal information (Harrison, Price, Gavin, and Florey, 2002).

A major source of deep level diversity in global virtual teams is the difference in cultural of the team members. Culture is defined as the set of deep level values shared by an identifiable group of people (Maznevski, Gomez, and Noorderhaven, 1997). Cultural values influence the perceptual filter through which a person interprets information needed to make decisions (Adler, 1997; Hofstede, 1980). In a global virtual team, different members' analyses and interpretation of facts and events can differ significantly depending on his/her national cultural background. Another form of team diversity is functional diversity, which refers to the total number of specialties of team members. Functional diversity has been found to be both positively and negatively associated with team effectiveness (Sundstrom, McIntyre, Halfhill, and Richards, 2000). The diversity can improve a team's ability to communicate with external parts of the organization, but it can adversely affect internal group processes such as increasing conflict and reducing cohesion within the team (Ancona and Caldwell, 1992). Previous research indicated that team members with similar functions share a common language and orientation which makes communication easier (Kiesler, 1978), and some studies has shown that greater functional diversity is related to lower performance (Haleblian and Flinkelstein, 1993). A variation of functional diversity is educational specialization diversity, which "relates to the different sets of task-relevant skills, knowledge, and abilities team members possess as a function of their educational backgrounds" (Dahlin, Weingart, and Hinds, 2005, page 1008). However, there is a difference between the functional diversity and educational specialization diversity. As Dahlin, Weingart, and Hinds (2005) suggest, functional areas have distinctive characteristics and represent to some extent social categorizations in organizations. Moreover, functional areas are subjected to organizational goals and objectives; in contrast, a team member's dominant educational background (i.e. his/her specialization) has less distinctive attributes that can be ascribed to a social category. Educational backgrounds shape how an individual processes information. We consider that educational specialization diversity is less constrained and more fundamental issue than functional diversity. Moreover, it is an unexplored construct in the research on virtual teams. Thus, we focus on educational specialization diversity in this research.

Prior research demonstrates that team diversity adversely affects the social integration of the team members (Tsui and Gutek, 1999) and shapes intra- 
group conflict (Pelled, Eisenhhardt, and Xin, 1999). Hinds and Wiseband (2003) propose that similarity in backgrounds facilitates the development of shared understanding in virtual teams. Gibson and Cohen (2003) define shared understanding as "the degree of cognitive overlap and commonality in beliefs, expectations, and perceptions about a given target" (page 33). Hinds and Wiseband (2003) define shared understanding in virtual team as "a collective way of organizing and communicating relevant knowledge, as a way of collaborating" (page 23). Virtual teams need to develop shared understanding about their goals, tasks, and group processes (Cohen and Gibson, 2003). Factors that contribute to the development of shared understanding are having similar backgrounds and experiences, communicating openly, sharing information and experiences, and developing team spirit (Hinds and Weisband, 2003). The members of global virtual teams have different cultural and educational specialization backgrounds because of which the collective way to organize and share information in team may be difficult. We expect that the individual members of these teams will perceive that the team has not developed high level of shared understanding. Hence:

Conjecture 3: In short duration virtual teams, cultural diversity will have a negative relationship with individual team member's perception of shared understanding in the team.

Conjecture 4: In short duration virtual teams, educational specialization diversity will have a negative relationship with individual team member's perception of shared understanding in the team.

Conflict is broadly defined as the perception by the parties involved that they hold discrepant views or have interpersonal incompatibilities (Boulding, 1963). In the context of group work, manifested conflict is a group level phenomenon while the perception of conflict occurs at the individual level of the members of the group. Perception of team conflict is the awareness of a latent conflict condition (Pondy, 1967). In the context of virtual team, team diversity is an antecedent condition in a group. Because of team diversity, there may be subunits with differing goals and values. This creates a latent condition for conflict. Thus, we expect that team diversity will result in perceived team conflict. Hence:

Conjecture 5: In short duration virtual teams, cultural diversity will have a positive relationship with individual member's perception of team conflict.
Conjecture 6: In short duration virtual teams, educational specialization diversity will have a positive relationship with individual member's perception of team conflict.

\section{Research methodology 3.1. Subjects}

A total of 72 students $(62.5 \%$ graduates, and $37.5 \%$ undergraduates) majored in business, computer and engineer from a large Midwestern university in the United States were involved in the research. On average, they were 24 years old and had 2 years of work experience. All subjects were volunteers and received extra credit for their participation. Subjects were randomly assigned to 24 teams, with 3 members in each. Teams were then randomly assigned to treatments.

\subsection{Variable identification}

This study involved three independent variables (i.e. team atmosphere, national cultural diversity, and educational specialization diversity) and two dependent variables (development of shared understanding and team conflict). Group atmosphere, development of shared understanding, and team conflict were measured using 5-point Likert scale questionnaires. The questionnaire items are listed in Table 1. The data collected for the development for shared understanding and team conflict were reverse coded to measure the constructs. In this study, we operationalized individual member's perception of group atmosphere by using a seven-item composite measure which had questions on trust and commitment. This is consistent with prior studies on group atmosphere (Jehn, Rispens, and Thatcher, 2010). We measured shared understanding by using two items that measured Individual member's perception of the shared understanding about interaction and activities of the team members.

National Cultural Diversity and Educational Specialization Diversity: We collected the demographic data of each participant, which was used to calculate national cultural and educational diversities. The participants indicated their nationalities and areas of specialization (i.e. majors). Each nationality was considered as a category of national culture. Similarly, each area of major was considered as a category of educational specialization. Following the standard approach for categorical variables, we calculated entropy-based index (Teachman, 1980) to measure national culture and educational specialization diversities. The entropybased index was calculated as:

Diversity $=\sum-\mathrm{Pi} \ln (\mathrm{Pi})$ 
Where, Pi indicates the proportion of group members belonging to each category of diversity. Thus, if all three members of a group were U.S. nationals, the national cultural diversity index would be 0.000 . In a group that had two U.S. and one Indian nationals, the diversity index was calculated as 0.637. Similarly, if all three members of a group were finance majors, the educational specialization diversity index would be 0.000 . In a group that had two finance majors and one operations management major, the diversity index was calculated as 0.637 .

\begin{tabular}{|c|c|}
\hline \multicolumn{2}{|c|}{ Table 1. Summary of Measurement Scales } \\
\hline Construct & Measure \\
\hline $\begin{array}{l}\text { Group } \\
\text { Atmosphere }\end{array}$ & $\begin{array}{l}\text { - We can freely share our } \\
\text { ideas, feelings, and hopes. } \\
\text { - If I shared my problems with } \\
\text { my members, I know they } \\
\text { would respond constructively } \\
\text { and caringly. } \\
\text { My members approached } \\
\text { their jobs with } \\
\text { professionalism } \\
\text { dedication. } \\
\text { - I can rely on my members not } \\
\text { to make my job more difficult } \\
\text { by careless work. } \\
\text { I feel enthusiasm about the } \\
\text { teamwork. } \\
\text { As a team, we tried our best } \\
\text { to do the work. } \\
\text { The more effort we put into } \\
\text { the project, the more we } \\
\text { gained from the teamwork. }\end{array}$ \\
\hline $\begin{array}{l}\text { Shared } \\
\text { understanding }\end{array}$ & $\begin{array}{l}\text { - It is difficult for us to build a } \\
\text { sharing and emotional } \\
\text { relationship in the team. } \\
\text { - It is difficult for us to } \\
\text { integrate the information } \\
\text { provided by each member. }\end{array}$ \\
\hline Team conflict & $\begin{array}{l}\text { - Our group was able to reach a } \\
\text { consensual solution without } \\
\text { any major conflict }\end{array}$ \\
\hline $\begin{array}{ll} & \text { Scale: } 1 \\
& \text { agree) }\end{array}$ & trongly disagree) to 5 (Strongly \\
\hline
\end{tabular}

\subsection{Task description}

McGrath (1984) differentiates between the problem-solving and decision making tasks. A problem-solving task has a demonstrable correct answer whereas a decision making task has a solution that is reflects the collective preference of group members. The task chosen for this study is a problemsolving task that has a demonstrable correct answer. Given that all participants have the learning experience of database management and application, the task chosen was to design a data model (Entity Relationship Diagram) for a database application. Each participant was provided with one page of introduction paper which listed four piece of unique information. The unique information provided the participants regarding the entities, attributes, cardinalities, and relationships that should be used for designing the database. The participants were asked to share information anonymously and synchronously and draw an entity relationship diagram (ERD) by using ER Assistant 2.10, a CASE tool. The ERD was the final solution provided by the group. Stasser (1992) have used this kind of hidden profile tasks (i.e. where each group member has unique yet complimentary information) to examine information sharing. This type of task is important for group laboratory research because it simulates an important characteristic of "real-world" tasks where each member holds unique information (Mennecke, 1997).

\subsection{Collaboration tool and training}

The tool used in our experiments was Lotus Sametime, a type of software for group collaboration over the Internet. As a synchronous groupware application, Sametime facilitates communication among geographically dispersed coworkers. The tool provides support on text message exchange, screen sharing, program sharing, whiteboard, audioconferencing, video-recording, and allows for voting on and ranking of the solution. Subjects were scheduled into four one-hour training sections to be orientated to the phases of the experiment and features of the software as well as the CASE tool used in the experiment.

\subsection{Experimental procedures}

Subjects were randomly assigned to one of four conditions: (1) participants working under time pressure, (2) participants working under reward inspiration, (3) participants working under both time pressure and reward inspiration, and (4) control participants working under no special treatment. The teams under time control were told to make decision quickly each 20 minutes: "Since it is very important to do the project efficiently, you need to come up with your solution quickly," and in order to make time more 
salient, after each 10 minutes they were informed of the remaining time. The teams under reward control were given a special offer emphasizing effectiveness of performance: "If your group can find the best solution for Henry Books, each of your members may get maximum 5 points beyond the 10 bonus points you obtain from the participation."

Members in each group were assigned to three different rooms and work on laptop workstations equipped with a mouse. One of the researchers acted as the facilitator from a separate room and monitors the group work. The activities experienced by groups included: (1) Group members participated in a discussion and distributed several pieces of information on hand. (2) Group members selected one from within the group to draw the ERD (referred to as Drawer). The drawing process was observable by other members at same time. The other members could not directly modify the diagram but ask the drawer to do so. (3) Once the group finished the ERD, the group members completed a posttest questionnaire that collected demographic data and psychological factors. All teams were given 60 minutes to finish the process before being surveyed. According to the two pilot studies conducted on graduate students, 60 minutes were long enough to complete the first two activities associated with the study.

\section{Results}

\subsection{Reliability and validity}

In Table 2 we present the reliability and validity statistics for the constructs used in the study. Since the measurement scales used had not been tested and validated adequately for virtual teams, a cut-off value 0.70 for Cronbach's Alpha was considered acceptable (Nunnally, 1978).

To examine convergent validity, factor analyses employing VARIMAX orthogonal rotation was carried out. The reliability and validity results are presented in tables 2. The items measuring group atmosphere loaded on a single factor and the Cronbach's alpha coefficient for the scale was 0.831 . We, therefore, used the aggregated scale as a measure of individual member's perception of group atmosphere. The items measuring shared understanding atmosphere loaded on a single factor and the Cronbach's alpha coefficient for the scale was 0.689 .

\begin{tabular}{|l|c|c|}
\hline \multicolumn{3}{|c|}{ Table 2. Convergent validity test } \\
\hline Constructs & $\begin{array}{c}\text { Cronbac's } \\
\text { Alpha }\end{array}$ & $\begin{array}{c}\text { Factor } \\
\text { Loadings }\end{array}$ \\
\hline Group atmosphere & 0.831 & $0.511-0.803$ \\
\hline Shared understanding & 0.689 & 0.873 \\
\hline
\end{tabular}

\subsection{Testing Conjectures}

This is a multilevel model. We used PROC MIXED of SAS to test our conjectures. Level 1 is the individual team member and level 2 is the team as a whole. The outcome control involved two categories for time pressure.

We built four models for each dependent variable. These are:

- Model 1: No predictor; just random effects of intercepts.

- Model 2: Model 1 plus level-1 fixed effects.

- Model 3: Model 2 plus random slopes for level-1 predictors.

- Model 4: Model 3 plus level-2 fixed effects.

The results are shown in tables 3 and 4 . We calculated Intraclass correlation coefficient for (ICC) from Model 1 of each dependent variable. ICC for shared understanding is 0.2392 which implies that $23.92 \%$ of the variability in shared understanding is accounted for by the teams. ICC for perceived team conflict is 0.2963 i.e. $29.63 \%$ of the variability in perceived team conflict is accounted for by the teams. The large variabilities in shared understanding and perceived team conflict are explained by the teams. This justifies the use of multi-level models to test the hypotheses of our study.

We find that the perception of group atmosphere has positive relationship with the development of shared understanding and a negative relationship with perceived team conflict $(\beta=0.598$ and $\beta=-0.923$ respectively). This provides support for our conjectures 1 and 2. We examined the effects of the team diversity (cultural diversity and educational specialization diversity) on the development of shared understanding and perceived team conflict. Cultural diversity has a positive effect on the development of shared understanding $(\beta=0.517)$. Thus, conjecture 3 is not supported because the results are significant in the opposite direction. Cultural diversity does not have any significant effect on perceived team conflict. We also did not find any significant effect of educational specialization diversity on the development of shared understanding and perceived team conflict. Thus, C4, C5, and C6 are not supported in this study. We included the treatment variables (time pressure and reward) in the multi-level models. The treatment conditions do not have any effect on shared understanding and perceived conflict. More specifically, when controlling for group atmosphere and team diversity the shared understanding and perceived conflict of the members in the teams under treatment conditions are not significantly different 
from the shared understanding and perceived conflict of the members in control teams.

\begin{tabular}{|c|c|c|c|c|}
\hline \multicolumn{5}{|c|}{ Table 3. Results for Fixed Effects for Shared } \\
Understanding \\
\hline Effect & $\begin{array}{c}\text { Estimate } \\
\text { (Std. } \\
\text { Error) }\end{array}$ & df & $\mathbf{t}$ value & Pr>|t| \\
\hline Intercept & $\begin{array}{c}1.638 \\
(0.653)\end{array}$ & 71.9 & 2.51 & $<0.015$ \\
\hline $\begin{array}{c}\text { Group } \\
\text { atmosphere }\end{array}$ & $\begin{array}{c}0.598 \\
(0.139)\end{array}$ & 71.2 & 4.30 & $<0.0001$ \\
\hline $\begin{array}{c}\text { Time } \\
\text { Pressure }\end{array}$ & $\begin{array}{c}0.213 \\
(0.157)\end{array}$ & 24.1 & 1.36 & 0.187 \\
\hline Reward & $\begin{array}{c}-0.007 \\
(0.157)\end{array}$ & 23.8 & -0.05 & 0.963 \\
\hline $\begin{array}{c}\text { Cultural } \\
\text { diversity }\end{array}$ & $\begin{array}{c}0.517 \\
(0.239)\end{array}$ & 23.7 & 2.16 & 0.0416 \\
\hline $\begin{array}{c}\text { Educational } \\
\text { diversity }\end{array}$ & $\begin{array}{c}-0.345 \\
(0.317)\end{array}$ & 24.2 & -1.09 & 0.287 \\
\hline
\end{tabular}

\begin{tabular}{|c|c|c|c|c|}
\hline \multicolumn{6}{|c|}{ Table 4. Results for Fixed Effects for Perceived } \\
Team Conflict \\
\hline Effect & $\begin{array}{c}\text { Estimate } \\
\text { (Std. } \\
\text { Error) }\end{array}$ & df & $\mathbf{t}$ value & Pr $>|\mathbf{t}|$ \\
\hline Intercept & $\begin{array}{c}5.729 \\
(0.777)\end{array}$ & 72 & 7.38 & $<0.0001$ \\
\hline $\begin{array}{c}\text { Group } \\
\text { atmosphere }\end{array}$ & $\begin{array}{c}-0.923 \\
(0.165)\end{array}$ & 71.1 & -5.59 & $<0.0001$ \\
\hline $\begin{array}{c}\text { Time } \\
\text { Pressure }\end{array}$ & $\begin{array}{c}0.214 \\
(0.187)\end{array}$ & 23.1 & -1.25 & 0.266 \\
\hline Reward & $\begin{array}{c}-0.234 \\
(0.187)\end{array}$ & 23.1 & -1.25 & 0.223 \\
\hline $\begin{array}{c}\text { Cultural } \\
\text { diversity }\end{array}$ & $\begin{array}{c}-0.059 \\
(0.286)\end{array}$ & 23 & -0.21 & 0.839 \\
\hline $\begin{array}{c}\text { Educational } \\
\text { diversity }\end{array}$ & $\begin{array}{c}0.474 \\
(0.379)\end{array}$ & 23.5 & 1.25 & 0.224 \\
\hline
\end{tabular}

\section{Discussion}

Our research highlights the importance of group atmosphere in shaping the perceptions of the individual members of the short duration virtual teams. We find that group atmosphere has positive relationship with the perception of shared understanding and a negative relationship with perceived conflict in short duration virtual teams in our study. We included trust and commitment in our conceptualization of group atmosphere. Although we used a composite measure of group atmosphere to test our conjectures, we conducted additional multi-level analyses by including trust and commitment as separate constructs and found similar relationships with the perception of shared understanding and perceived conflict. Trust has a positive relationship with shared understanding $(\beta=0.387, p=0.034)$ and a negative relationship with perceived conflict $(\beta=-0.279, \mathrm{p}=0.039)$. Commitment has a positive relationship with shared understanding $(\beta=0.444, p=0.059)$ and a negative relationship with perceived conflict $(\beta=-0.674, \mathrm{p}=0.0002)$.

We also find that cultural diversity positive relationship with the development of shared understanding in short duration virtual teams. The finding contradicts the proposed relationship between cultural diversity and shared understanding. We found that cultural diversity facilitates shared understanding in the team involved in our study. An explanation for this finding is drawn from attribution theory (Kelly, 1973). When individuals see discrepancies in behaviors, they attribute those discrepancies to either the individual or something in the situation. Attribution theory (Kelly, 1973), refers to these as internal or external reasons in the perception of causation. When individuals come from different cultures, they may attribute at least some of the causes of conflict to misunderstandings due to differences in national culture - a cause that is external to the individual and thus one that is not the "fault" of the individual. They may try to understand the cause of disagreement. In the process the shared understanding improves.

We did not find any support for the proposed relationships of educational specialization diversity with the shared understanding and perceived conflict in our study teams. It is possible that all participants in our experiment were familiar with the task of the experiment. Most of these students had taken courses on database management. Thus, educational specialization diversity was not a source of variance in the development of shared understanding and perceived conflict in these teams.

\section{Conclusion}

Although this study marks the beginning of research short-duration virtual teams, we can draw some conclusions from this research. We find that the perceived group atmosphere in plays a crucial role in short duration virtual teams. We also find that national cultural diversity does facilitate the development of shared understanding in short duration virtual teams. These findings provide motivation to conduct in depth studies on group atmosphere, shared understanding, and conflict in virtual teams. 


\section{References}

[1] Adler, N. J. International Dimensions of Organizational Behavior, South-Western College Publishing, Cincinnati, OH, 1997.

[2] Ancona, D. G., and Caldwell, D. E., "Demography and design: Predictors of new product team performance," Organization Science: A Journal of Institute of Management Sciences (3) 1992, pp.321-342.

[3] Boulding, K. 1963. Conflict and Defense, Harper and Row, New York, NY.

[4] Bunce, D., M. A. West. 1995. Self-perceptions and perceptions of group climate as predictors of individual innovation at work. Applied Psychology, 44(3) 199-215.

[5] Burningham, C., M. A. West. 1995. Individual, climate, and group interaction processes as predictors of work team innovation. Small group research. 26(1) 106-117.

[6] Chidambaram, L. "Diversity: Is there more than meets the eye?" Proceedings of the Thirty-Eighth Annual Hawaii International Conference on Systems Sciences, Los Alamitos, CA: IEEE Computer Society Press, 2005.

[7] Choi, J. N., R. H. Price, A. D. Vinokur. 2003. Self- efficacy changes in groups: effects of diversity, leadership, and group climate. Journal of Organizational Behavior. 24(4) 357-372.

[8] Dahlin, K.B., Weingart, L.R., and Hinds, P.J. "Team Diversity and Information Use," Academy of Management Journal (48:6), 2005, pp. 1107-1123.

[9] Davis, D.D., "The Tao of leadership in virtual teams", Organizational Dynamics, 33, 1, 2004, 47-62.

[10] De Dreu, C. K. W. and Weingart, L. R. 2003. "Task Versus Relationship Conflict, Team Performance, and Team Member Satisfaction: A Meta- Analysis,” Journal of Applied Psychology (88:4), pp. 741-749.

[11] De Pillis, E. and Furumo, K. "Counting the cost of virtual teams," Communications of the ACM, 50, 12, 2007, pp. 93-95.

[12] Dube, L. and Pare, G. "The Multi-faceted Nature of Virtual Teams," Working Paper, ISSN 0832-7203, November 2002, pp. 1-33.

[13] Gibson, C. B., J.L. Gibbs. 2006. Unpacking the concept of virtuality: The effects of geographic dispersion, electronic dependence, dynamic structure, and national diversity on team innovation. Administrative Science Quarterly. 51(3) 451-495.

[14] Guetzkow, H. and Gyr, J. 1994. "An analysis of conflict in decision making groups," Human Relations 7, pp. 367-381.

[15] Haleblian, J. and Finkelstein, S. "Top Management Team Size, CEO Dominance, and Firm Performance: The Moderating Roles of Environmental Turbulence and Discretion," Academy of Management Journal (36:4), 1993, pp. 844-863.

[16] Han, H.J., Hiltz, S.R., Fjermestad, J. and Wang, Y. 2011. "Does the Medium Matter? A Comparison of Initial Meetings Modes for Virtual Teams," IEEE Transactions on Professional Communications, 54(4), 376-391

[17] Handy, C., "Trust and the virtual organization", Harvard Business Review, 73, 1995, 40-50.
[18] Harrison, D. A., Price, K. H., and Bell, M. P. "Beyond relational demography: Time and the effects of surfaceand deep-level diversity on work group cohesion," Academy of Management Journal (41), 1998, pp. 96107.

[19] Harrison, D.A., Price, K. H., Gavin, J. H., and Florey, A. T. "Time, Teams, and Task performance: Changing effects of surface- and deep level diversity on group functioning," Academy of Management Journal (45:5), 2002, pp. 1029-1045.

[20] Hinds, P. J. and Bailey, D. E. 2000. "Virtual teams: Anticipating the impact of virtuality on team process and performance," In Proceedings of Academy of Management, Ontario, Toronto, Canada

[21] Hinds, P. and Weisband, S. P. (2003). Knowledge sharing and shared understanding in virtual teams. In C. B. Gibson \& S. G. Cohen (Eds.), Virtual Teams That Work (pp. 21-36). San Francisco, CA: Jossey-Bass.

[22] Hofstede, G. Culture's Consequences: International Differences in Work-Related Values, Sage, Newbury Park, CA, 1980.

[23] Jackson, S. E., May, K. E., and Whitney, K. "Understanding the dynamics of diversity in decision making teams," in Team decision-making effectiveness in organizations, R. A. Guzzo and E. Salas (Eds.), Jossey-Bass, San Francisco, 1995, pp. 204-261.

[24] Jarvenpaa, J.S., Knoll, K., and Leidner, D.E., "Is anybody out there? Antecedents of trust in global virtual teams", Journal of Management Information Systems, 14, 4, 1998, 29-64.

[25] Jehn, K. and Mannix, E. A. "The Dynamic Nature of Conflict: A Longitudinal Study of Intragroup Conflict and Group Performance," Academy of Management Journal (44:2), 2001, pp. 238-251.

[26] Jehn, K. A., Northcraft, G. B., and Neale, M. A. 1999. "Why differences make a difference: A field study of diversity, conflict and performance in workgroups," Administrative Science Quarterly (44:4), pp. 741-763.

[27] Jehn, K. A. Rispens, S., and Thatcher, S. M. B. "The effects of conflict asymmetry on work group and individual outcomes," Academy of Management Journal 53(3), pp. 596-616.

[28] Kiesler, S.B. "Interpersonal Processes in Groups and Organizations," Arlington Heights, Ill.: AHM Publishing, 1978.

[29] Klimoski, R. and Mohammed, S. (1994). "Team Mental Model: Construct or Metaphor?" Journal of Management 20(2), pp. 403-437.

[30] Lind, M. R. (1999). The gender impact of temporary virtual work groups. IEEE transactions on professional communication, 42(4), 276-285.

[31] Mathieu, J., Goodwin, G.F., Heffner, T.S, Salas, E., and Cannon-Bowers, J.A. (2000). "The Influence of Shared Mental Models on Team Process and Performance," Journal of Applied Psychology 85(2), pp. 273-283.

[32] Maznevski, M.L., Gomez, C.B., and Noorderhaven, P.W. "The cultural orientations framework and international management research," Presented at the Academy of International Business Annual Meeting, Las Vegas, NV, 1997, pp. 227-231. 
[33] McAllister, D.J., “Affect- and cognition-based trust as foundations for interpersonal cooperation in organizations", Academy of Management Journal, 38, 1, 1995, 24-59.

[34] McGrath, J.E., Groups: Interaction and Performance, Prentice-Hall, 1984.

[35] Mohammed, S. and Dumville, B.C. (2001). "Team mental models in a team knowledge framework: expanding theory and measurement across disciplinary boundaries," Journal of Organizational Behavior 22, pp. 89-106.

[36] Montoya-Weiss, M. M., A. P. Massey, M. Song. 2001. Getting it together: Temporal coordination and conflict management in global virtual teams. Academy of Management Journal. 44(6) 1251-1262

[37] Nunnally, J., Psychometic theory, McGraw-Hill, New York, 1978.

[38] Orasanu, J. (1990). Shared mental models and crew decision making.

[39] Orasanu, J. and Salas, E. (1993). Team decision making in complex environments. In G.A. Klein, J. Orasanu, R. Calderwood, and C.E. Zsambok (Eds.) Decision masking in action: models and methods. Norwood, NJ: Ablex.

[40] Parker, C. P., B. B. Baltes, S. A. Young, J. W. Huff, R. A. Altmann,. H. A. Lacost, J. E. Roberts.2003. Relationships between psychological climate perceptions and work outcomes: outcomes: a meta- analytic review. Journal of Organizational Behavior. 24(4) 389-416.

[41] Paul, S., S. Ray. 2010. Manifested Intra-Group Conflict in Collaborative Technology Supported Multi-Cultural Virtual Teams: Findings from a Laboratory Experiment. In Proceedings of the 43rd Hawaii International Conference on System Sciences, Kauai, HI.

[42] Pelled, L. H., Eisenhardt, K. M., and Xin, K. R. 1999. "Exploring the black box: An analysis of work group diversity, conflict, and performance," Administrative Science Quarterly (44:1), pp. 1-28.

[43] Pondy, L.R., "Organizational Conflict: Concept and Models", Administrative Science Quarterly (12), 1967, pp 296-320.

[44] Poole, M. S., Holmes, M., and DeSanctis, G. 1991. "Conflict management in a computer-supported meeting environment," Management Science, 37(8), pp. 926953.

[45] Powell, A., Piccoli, G, and Ives, B., "Virtual teams: a review of the current literature and directions for future research", The DATA-BASE for Advances in Information Systems, 35, 1, 2004, 6-36.

[46] Stahl, G. K., Maznevski, M. L., Voigt, A., and Jonsen, K. 2010. "Unraveling the effects of cultural diversity in teams: A meta-analysis of research on multicultural work groups," Journal of international business studies 41(4), pp. 690-709.

[47] Stout, R.J., Canon-Bowers, J.A., Salas, E., and Milanovich, D.M. (1999). "Planning, shared mental models, and coordinated performance: An Empirical Link is Established," Human Factors, 41(1), pp. 61-71.

[48] Sundstrom, E., McIntyre, M., Halfhill, TR, \& Richards, H. "Work groups: From the Hawthorne studies to work teams of the 1990s and beyond," Group Dynamics: Theory, Research, and Practice (4), 2000, pp.41-67.

[49] Teachman, J.D. "Analysis of Population diversity," Sociological Methods and Research, 8, 1980. pp. 341362.

[50] Thatcher, S. M., Jehn, K. A., and Zanutto, E. 2003. "Cracks in diversity research: The effects of diversity faultlines on conflict and performance," Group Decision and Negotiation 12(3), pp. 217-241.

[51] Walther, J. B. $1996 . \quad$ Computer-Mediated Communication: Impersonal, Interpersonal, and Hyperpersonal Interaction. Communication Research. 23(1) 3-43.

[52] Zarraga, C., J. Bonache. 2005. The impact of team atmosphere on knowledge outcomes in self-managed teams. Organization Studies, 26(5) 661-681.

\section{Appendix I}

The Screen Provided by a Group as the Final Solution

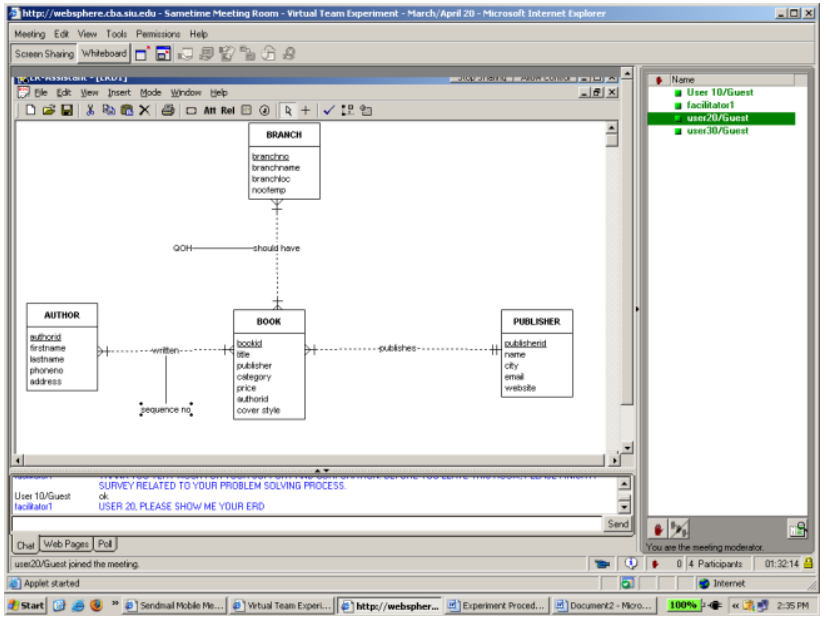

